\title{
Behavior problems and social competence in Brazilian children with specific language impairment
}

\author{
Marina Leite Puglisi ${ }^{1 *}$, Ana Manhani Cáceres-Assenço², Thays Nogueira ${ }^{2}$ and Debora Maria Befi-Lopes²
}

\begin{abstract}
This study aimed to investigate the behavior and social profile of Brazilian children with specific language impairment (SLI) and explore whether the severity of language deficits was associated with behavioral problems and low social competence. Twenty-four children with SLI aged from 6 to 11 years who showed substantial expressive language problems and were receiving speech-language therapy were assessed through the Child Behavior Checklist (CBCL). Children with SLI showed high rates of behavioral problems and low levels of social competence. With the exception of two subscales ("somatic" and "rule breaker"), the percentage of children with SLI at risk of behavioral problems was significantly higher than the same proportion in the general population; and almost all children with SLI (95.2\%) demonstrated problems with social competence. The severity of language deficits was associated with the risk of behavioral problems according to only one criterion. No associations were found between the severity of language problems and social competence. The study provides cross-cultural evidence to support the existence of behavior problems and reduced social competence in children with SLI. Our findings point to the need of using a combination of measures to classify the severity of language problems rather than a single dimension.
\end{abstract}

Keywords: Social skills, Behavior problems, Social communication, Language disorders, Developmental disorders

\section{Background}

Specific language impairment (SLI) is a persistent developmental disorder that affects language development and is not secondary to intellectual impairment, brain damage, sensorial or psychiatric problems (Stark and Tallal 1981). Although the diagnostic criterion for SLI excludes psychiatric disorders, there is a consistent association between language impairment and behavioral problems (St Clair et al. 2011; Van Agt et al. 2011; van Daal et al. 2007; Yew and O'Kearney 2013; Gregl et al. 2014; Mok et al. 2014; Hollo et al. 2014; Helland et al. 2014). The causal path of this relation remains unclear, but evidence from longitudinal studies suggests the direction of effect may be from language to behavior (Petersen et al. 2013).

According to this model, language disorders might limit the ability to express wishes, needs and emotions, which in turn causes a negative impact on peer relations (St Clair

\footnotetext{
*Correspondence: marinapuglisi@uol.com.br

'Universidade Federal de São Paulo, Sao Paulo, Brazil

Full list of author information is available at the end of the article
}

et al. 2011) and increases the risk of oppositionalaggressive behavior, withdrawn social profile and social anxiety (Macharey and von Suchodoletz 2008). A number of studies have shown indeed that language-impaired children not only demonstrate behavioral problems, but also show lower levels of social competence (Lindsay et al. 2002; Macharey and von Suchodoletz 2008; Schoon et al. 2010), particularly in aspects related to pro-social initiatives and likeability (Hart et al. 2004).

Considering the severity and persistency of SLI, behavioral and social problems tend to increase with age, as a consequence of victimization and stigmatization over prolonged periods of time (Brinton and Fujiki 2005). Conti-Ramsden and Botting have conducted a series of longitudinal studies to understand the relation between age and the behavioral profile of children with SLI. The findings revealed that behavioral and emotional problems increased during childhood and school years (Botting and Conti-Ramsden 2000; Conti-Ramsden and Botting 2004), but decreased up to adulthood - even 
though emotional problems still remained above population norms (St Clair et al. 2011). Social problems, however, constantly increased during the same period of time (Botting and Conti-Ramsden 2000; Conti-Ramsden and Botting 2004; St Clair et al. 2011), being strongly and chronically associated to SLI. In another series of studies, Mok et al. (2014) analysed the longitudinal trajectories of peer relations in children with specific language impairment. They found that $78 \%$ of SLI children had problems with peer relations at one point (childhood, adolescence or both) and the risk of poor trajectories was greater for those children with pragmatic language difficulties.

Taken together, these findings heavily support the relation between language and social behavior and reinforce behavioral and social problems in children with language impairment. It is not clear, however, if this relation remains the same within clinical samples, particularly within a group of SLI children. If language abilities do influence behavior and social competence in a linear way for all groups of children, the severity of SLI should be closely related to behavioral problems and low social competence. However, scientific evidence suggests this is not always the case.

Hart et al. (2004) have tested this hypothesis by comparing the social and behavioral profile of children with SLI having moderate and severe language impairment on a standardized language assessment (CELF-R, Semel et al. 1987). The findings indicated that the severity of SLI appeared to be related to two types of sociable skills, but not to most withdrawn behaviors, impulse control and likeability (Hart et al. 2004). This has led to the conclusion that the relation between sociable behaviors and language skills in SLI stands only for initiatives that are largely carried out by using language. Lindsay and Dockrell (2012) have reinforced this by showing that early language abilities of children with a history of SLI did not predict general behavioral difficulties or the development of self-concepts at the age of 16 . Both groups of researchers have argued that social problems may stem from multiple sources, and it is important to explore the interaction between cognitive, emotional and language abilities in order to have a better picture of the social outcomes in children with SLI.

Other studies of children with SLI, on the other hand, did find that language competence was generally a good predictor of behavior, particularly when aspects such as grammar, semantics and pragmatics were taken into account (van Daal et al. 2007). Similarly, Van Agt et al. (2011) have found that both receptive and expressive language deficits were closely associated with attention problems, aggressiveness and worse quality of life in SLI.

The absence of a consensus in the field shows that the relation between language, behavior and social competence within a clinical SLI sample is complex and remains an open question. If language is linearly related to behavior and social competence, as argued by Schoon et al. (2010), one might expect to find that children with severe language disorders have more behavioral problems and less social competence than children with mild to moderate language problems. If, on the other hand, variations in language skills among a group of children with language impairment are only related to behaviors that are largely dependent on language itself (Hart et al. 2004), we should expect to find significant associations between language and social competence, but not necessarily between language and behavior in general.

This study was designed to explore this theme in depth. We first calculated the percentage of behavioral problems and low social competence in a sample of 24 Brazilian children with SLI who were attending speech-language therapy, and compared it with the proportion of the same problems in a representative sample of TD children. Behavior and social profile were assessed through the Child Behavior Checklist (CBCL; Bordin et al. 1995; Bordin et al. 2013) and language skills were evaluated by a combination of measures including the domains of semantics, phonology, syntax and pragmatics.

We then explored whether behavioral problems and low social competence were associated with the severity of language deficits. Considering that sampling procedures (particularly the methods through which severity of language problems is defined) may somehow account for the different research findings, we decided to adopt more than one criterion for classifying the severity of language disorders. The literature in the field uses different sorts of classification criteria, such as splitting groups through the median (Hart et al. 2004), identifying areas of impairment (van Daal et al. 2007; Lindsay and Dockrell 2012) or combining different criteria to analyze the pervasiveness of language problems (Van Agt et al. 2011). In the present study we adopted one criterion that considered the number of affected areas (comprehensive criterion) and another that combined both the number of affected areas and the size of the gap in each area (severity criterion).

In sum, answers to the following research questions were sought:

1. Do Brazilian school-aged children with SLI show more behavioral problems and less social competence than typically developing children?

Based on international literature, we expected to replicate previous findings showing behavioral problems and low social competence in Brazilian children with SLI. However, because no consensus has been reached on the prevalence of behavioral and social problems among 
children with SLI, we did not raise specific predictions, but rather expected to find a percentage ranging from approximately $40 \%$ (Beitchman et al. 1986; Willinger et al. 2003; van Daal et al. 2007) to 80 \% (Noterdaeme and Amorosa 1999).

2. Do children with SLI with severe language problems show more behavioral problems and less social competence than those with mild to moderate language problems?

We expected that children with severe language impairment would show less social competence - but not necessarily more behavioral problems - than children with mild to moderate language impairment. This hypothesis is based on the idea that social competence is highly dependent upon language to be performed; but behavior is less language oriented.

\section{Methods}

This was a cross-sectional study designed to investigate behavioral problems and social competence in a Brazilian sample of SLI children receiving speech and language therapy.

\section{Participants}

Participants were recruited in a public speech and language service exclusive for children with language impairment (total $n=55$ ). From the whole group of patients, 22 children were excluded from this sample because they were out of the age range of interest for this study; and other nine children were excluded because they did not complete the whole battery of language and/or cognitive tests. Our final sample comprised 24 children with SLI aged $6-11$ years ( $M=96.21$ months, $\mathrm{SD}=14.66$ months). Gender distribution in this sample was 5:1 (boys:girls). Although this rate is higher than reported in other studies, it reflects the higher prevalence of SLI in boys than girls (Whitehouse 2010). In order to select a relatively homogeneous group of children with SLI, our inclusion criteria consisted of performance below age-expected levels in at least three out of the five following tests: the Expressive Vocabulary Test (Befi-Lopes 2004); the Phonological Short-Term Memory Test (Rodrigues and Befi-Lopes 2013); the Comprehensive Test of Phonological Processing (CTOPP, Wagner et al. 1999); the Mean Length of Utterance (MLU, Araújo 2003); and the Pragmatic Test (Fernandes 2004). All children showed normal performance on nonverbal IQ.

All participants were studying in state schools in the city of São Paulo. Family income widely ranged from 0.86 to 27.58 minimum wages, but the vast majority of subjects came from low- to middle-SES households (Percentile $25=1.42$; Percentile $50=3.02$; Percentile $75=$
4.83). Table 1 presents the description of the sample, including information on socioeconomic status (parental educational level), gender, children's performance on nonverbal intelligence and language tests.

Children were classified into language subgroups according to two criteria. The first one took into account the number of tests children performed below ageexpected levels. This criterion was referred to as the "comprehensive criterion". Children were classified as having moderate language problems (poor performance on three or four language tests; $N=13,11$ of which were boys) or comprehensive language problems (poor performance in all five measures; $N=11,9$ of which were boys). It should be noticed that this is a qualitative criterion that only considers the number of areas children struggled with, regardless of the size of language problems.

The second criterion combined qualitative and quantitative approaches. It considered both the comprehensiveness of language problems and the size of the gap in each test. The size of the gap was calculated by the difference (in years) between children's chronological and linguistic age. Children were classified as having moderate language problems (less than or equal to a 2-yeargap in at least three tests; $N=10,7$ of which were boys) or severe language problems (more than a 2-year-gap in at least three tests; $N=14,13$ of which were boys). This was referred to as the "severity criterion".

\section{Measures and procedures}

The Brazilian version of the CBCL (Bordin et al. 1995, 2013) was employed to assess children's behavioral problems and social competence. The CBCL is an acknowledged assessment of children's behavior that has been widely used in international research on developmental disorders. It consists of a questionnaire to be filled out by the parents or children's caregivers. The respondent have to rate how often their child experiences various types of behavioral problems and how good their social competence is in different areas. The behavioral scale of the questionnaire consists of 118 items organized into eight subscales. Each item should be scored 0 (not true), 1 (somewhat or sometimes true) or 2 (very true or very often true). The Anxious/Depressed, Withdrawn/Depressed and Somatic Complaints subscales taken together constitute the Internalizing scale. The RuleBreaking Behavior and Aggressive Behavior subscales form the Externalizing scale. The remaining subscales are Social Problems, Thought Problems and Attention Problems. The component of CBCL designed to tap Competencies is assessed through 20 questions across three subscales: Activities, Social and School. In most items, parents need to classify the performance of their children as "below mean", "mean" or "above mean", in comparison to their peers of the same age. Following the 
Table 1 Description of the sample

\begin{tabular}{|c|c|c|}
\hline & Frequency & Percentage (\%) \\
\hline \multicolumn{3}{|l|}{ Educational status } \\
\hline \multicolumn{3}{|c|}{ Parental highest educational level $(N=24)$} \\
\hline Elementary school & 7 & 29.2 \\
\hline Middle school & 1 & 4.2 \\
\hline High school & 11 & 45.8 \\
\hline Post-secondary education & 5 & 20.8 \\
\hline \multicolumn{3}{|c|}{ Children's grade at school $(N=24)$} \\
\hline 1st Grade & 2 & 8.3 \\
\hline 2nd Grade & 13 & 54.2 \\
\hline 3rd Grade & 6 & 25.0 \\
\hline 4th Grade & 3 & 12.5 \\
\hline \multicolumn{3}{|l|}{ Gender } \\
\hline Male & 20 & 83.3 \\
\hline Female & 4 & 16.7 \\
\hline \multicolumn{3}{|c|}{ Children's intellectual performance } \\
\hline \multicolumn{3}{|c|}{ Children's nonverbal IQ ${ }^{\mathrm{a}}(N=24)$} \\
\hline Superior & 2 & 8.3 \\
\hline Above the mean & 6 & 25.0 \\
\hline Mean & 15 & 62.5 \\
\hline Below the mean & 1 & 4.2 \\
\hline \multicolumn{3}{|l|}{ Children's language performance } \\
\hline \multicolumn{3}{|l|}{ Expressive vocabulary $(N=24)$} \\
\hline Adequate & 1 & 4.2 \\
\hline 1-year gap & 6 & 25.0 \\
\hline 2-years gap & 4 & 16.7 \\
\hline More than 2-years gap & 13 & 54.2 \\
\hline \multicolumn{3}{|l|}{ Nonword repetition $(N=24)$} \\
\hline Adequate & 2 & 8.3 \\
\hline 1-year gap & 2 & 8.3 \\
\hline 2-years gap & 2 & 8.3 \\
\hline More than 2-years gap & 18 & 75.0 \\
\hline \multicolumn{3}{|c|}{ СTOPP (equivalent school grade) ${ }^{b}(N=24)$} \\
\hline Grade 2 & 1 & 4.2 \\
\hline Grade 1 & 3 & 12.5 \\
\hline Below Grade 1 & 20 & 83.3 \\
\hline \multicolumn{3}{|c|}{ Mean Length of Utterance $(N=23)$} \\
\hline 1-year gap & 3 & 13.0 \\
\hline 2-years gap & 6 & 26.1 \\
\hline More than 2-years gap & 14 & 60.9 \\
\hline \multicolumn{3}{|c|}{ Pragmatic (communication initiative) $(N=21)$} \\
\hline 1-year gap & 2 & 9.5 \\
\hline 2-years gap & 1 & 4.8 \\
\hline More than 2-years gap & 18 & 85.7 \\
\hline
\end{tabular}

${ }^{a}$ Children were assessed on either the WISC or RAVEN

${ }^{\mathrm{b}}$ All children showed at least one year of schooling gap discussion proposed by Del Prette et al. (2012), the term "social competence" will be employed in this study to define a construct that empirically derives from items assessing engagement in activities, social relationships and academic achievement. Therefore, we will hereinafter refer to the competence scale of the CBCL as "social competence".

Raw scores in the CBCL are transformed into $\mathrm{T}$ scores, having a mean of 50 and a $S D$ of 10 . According to the original criteria of the questionnaire, different cutoffs for each scale and subscale allow the examiner to classify children's reported performance into normal, borderline or clinical. It is also possible to analyze children's performance based on the percentile, for which specific cutoffs also exist.

\section{Analysis}

Parents' responses at the CBCL were scored by the examiner and converted into $\mathrm{T}$-scores and percentiles with the software Assessment Data Manager - ADM $8.1^{\circ}$. Children's T-scores in each scale and subscale of the CBCL were classified as normal, borderline or clinical according to Achenbach and Rescorla (2004). For the purposes of this study, the two deviant classifications (borderline and clinical) were grouped together and further relabeled as "at risk of" (cutoff criteria for each scale/subscale are presented in Table 2).

In order to target the first aim of this study, we initially calculated the percentage of SLI children classified as "at risk of" in each scale and subscale, separately. Using independent One Sample Chi-square Tests, we then compared these percentages (behavioral problems and low social competence in this research sample) to the proportion of children classified as "at risk of" in the general population (Achenbach and Rescorla 2004).

Following our second research question, we sought to investigate whether behavioral problems and low social competence were related to language deficits in a sample of children with SLI. We first employed qualitative analyses to explore the language profile of children at risk of behavioral problems and low social competence. The language profile was defined in terms of language subgroups, according to the two previously defined classifications: comprehensiveness and severity. Children's performance on the two main scales of the CBCL (behavioral problems and social competence) was plotted and data points were then labeled by language subgroups. We were interested to analyze whether different profiles would emerge for different language subgroups. The variables that appeared to be associated were then explored in details in subsequent Chi-square Tests.

\section{Ethical aspects}

This research was approved by the Ethics Committee of this University under the number $1101 / 09$ and all 
Table 2 Performance of SLI children on the CBCL

\begin{tabular}{|c|c|c|c|c|c|c|c|c|}
\hline & & \multicolumn{3}{|l|}{ T-scores } & \multicolumn{3}{|c|}{ Percentile } & \multirow{2}{*}{$\begin{array}{l}\text { Statistics } \\
\left(x^{2}\right)^{b}\end{array}$} \\
\hline & & Cutoff $^{a}$ & Mean & SD & Cutoff $^{a}$ & Mean & SD & \\
\hline \multirow[t]{8}{*}{ Behavior subscales } & Anxiety/Dep. & $<65$ & 59.04 & 7.50 & $<93$ & 76.13 & 17.95 & $11.95^{*}$ \\
\hline & Withdrawn/Dep. & $<65$ & 60.63 & 8.47 & $<93$ & 78.79 & 19.31 & $34.30^{* *}$ \\
\hline & Somatic & $<65$ & 55.21 & 7.10 & $<93$ & 65.42 & 17.49 & 1.12 \\
\hline & Social & $<65$ & 62.00 & 5.47 & $<93$ & 85.54 & 11.99 & $44.31^{* *}$ \\
\hline & Thought & $<65$ & 58.04 & 8.59 & $<93$ & 71.83 & 19.39 & $18.12^{*}$ \\
\hline & Attention & $<65$ & 61.00 & 7.19 & $<93$ & 81.54 & 13.78 & $11.95^{*}$ \\
\hline & Rule Breaker & $<65$ & 56.42 & 5.68 & $<93$ & 70.92 & 15.95 & 0.07 \\
\hline & Aggressive & $<65$ & 58.71 & 6.44 & $<93$ & 76.71 & 16.65 & $11.95^{*}$ \\
\hline \multirow[t]{3}{*}{ Behavior scales } & Internalizing & $<60$ & 58.04 & 10.56 & $<84$ & 71.63 & 28.16 & $20.64^{* *}$ \\
\hline & Externalizing & $<60$ & 57.33 & 7.10 & $<84$ & 72.58 & 20.38 & $8.25^{*}$ \\
\hline & Total behavior problems & $<60$ & 60.04 & 8.76 & $<84$ & 77.21 & 21.72 & $20.64^{* *}$ \\
\hline \multirow[t]{3}{*}{ Competence subscales } & Activities & $>35$ & 36.08 & 9.27 & $>7$ & 15.46 & 20.55 & $113.56^{* *}$ \\
\hline & Social & $>35$ & 40.96 & 7.91 & $>7$ & 24.33 & 19.01 & $18.12^{*}$ \\
\hline & School & $>35$ & 34.52 & 9.24 & $>7$ & 13.29 & 18.03 & $81.11^{* *}$ \\
\hline Competence scale & Total social competence & $>40$ & 32.76 & 6.66 & $>16$ & 7.67 & 11.65 & $98.10^{* *}$ \\
\hline
\end{tabular}

* Statistical significance at $p<.01 ; *$ Statistical significance at $p<.001$

${ }^{\text {a }}$ Normality range

b One Sample Chi-square Tests $(\mathrm{df}=1)$

participants had their consent form signed by their parents or caregivers.

\section{Results}

Children with SLI showed high rates of behavioral problems and low levels of social competence (Fig. 1). With the exception of two subscales ("somatic" and "rule breaker"), the percentage of SLI children at risk of behavioral problems was significantly higher than the same proportion in the general population (Fig. 1a). Internalizing problems were more frequent than externalizing problems (Fig. 1b). Almost all children with SLI (95.2 \%)

\section{a. Behavior subscales}

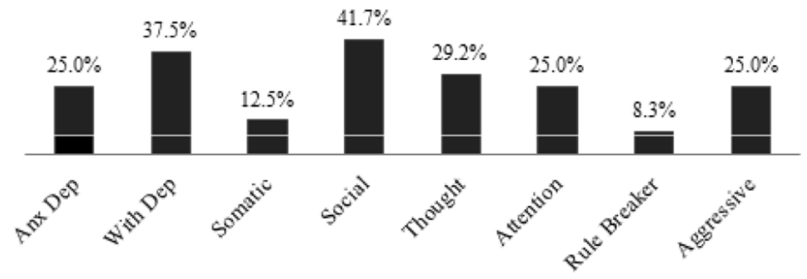

\section{b. Behavior scales}

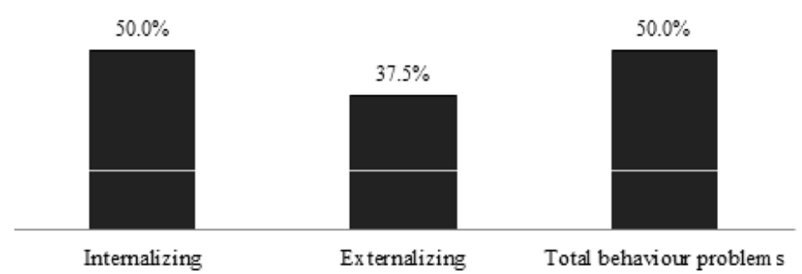

\section{C.Competence subscales}

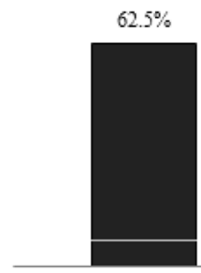

Activities

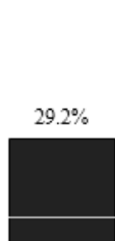

Social

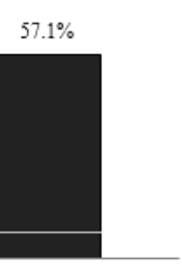

School

\section{d. Competence scale}

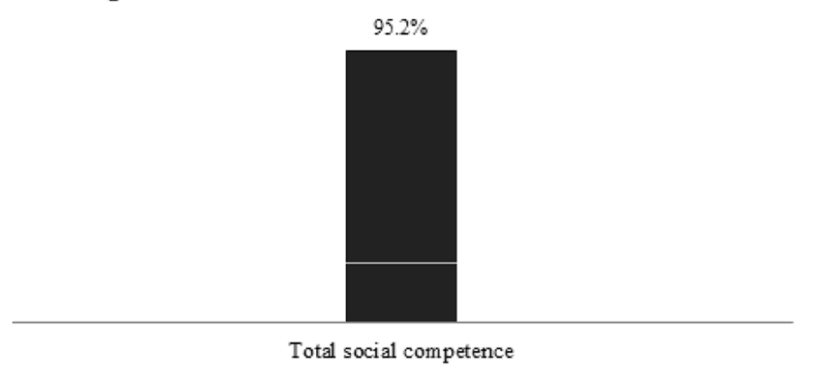

Fig. 1 Percentage of SLI children classified as "at risk of" in each scale and subscale of the CBCL. Horizontal lines inside the bars represent the prevalence of children classified as "at risk of" in the general population (Achenbach and Rescorla 2004). Panels $\mathbf{a}$ and $\mathbf{b}$ represent the percentage of at-risk children on the behavior subscale and scale, respectively. Panels $\mathbf{c}$ and $\mathbf{d}$ show the percentage of at-risk children on the competence subscale and scale, respectively 
demonstrated low social competence (Fig. 1d), which emerged mainly from the subscales "Activities" and "School" (Fig. 1c). Descriptive and inferential statistics are provided in Table 2.

To better understand the linguistic profile of the atrisk group, we explored the language classification of each child in scatterplots contrasting the total of behavioral problems and the total of social competence ( $\mathrm{T}$ scores). More specifically, we aimed to explore whether different patterns would emerge in function of children's language subgroups. Figure 2 shows the scatterplots for each language classification using the comprehensive (a) and severity (b) criteria.

The graphs clearly show that the severity criterion (b) - but not the comprehensive one (a) - was associated with the risk of behavioral problems in this sample: all children at risk of behavioral problems felt into the severe language group (more than a 2-year-gap in three or more areas). For social competence, no associations were found. All children except from one subject were classified as "at risk of" low social competence, leading to almost no variability in scores.

This qualitative analysis indicated the need for exploring the association between behavioral problems and the severity of language impairment in depth. To do this, we employed a series of Chi-square analyses having the binary classification of behavioral problems (normal vs. "at risk of") and the binary classification of language severity for each area, separately (moderate vs. severe) as the variables of interest. Table 3 indicates that the lexical and grammatical domains accounted for the significantly associations between the severity of language impairment and the classification of behavioral problems.

\section{Discussion}

We sought to investigate the behavior and social profile of Brazilian children with SLI and explore whether behavior problems and low social competence are associated with language deficits among this clinical group. This sample included a group of children with substantial expressive language problems, mainly from low- to mid-SES Brazilian families. We found that, similar to international studies, Brazilian children with SLI had more behavior problems and showed less social competence than the general population (Macharey and von Suchodoletz 2008; St Clair et al. 2011; Van Agt et al. 2011; van Daal et al. 2007). The percentage of children in this sample classified as "at risk of" total behavior problems (50\%) was higher than rates reported in previous studies with younger children (van Daal et al. 2007; Willinger et al. 2003), but lower than those from German language-impaired children from the same age range (Noterdaeme and Amorosa 1999). Behavior problems included both internalizing and externalizing difficulties, but were more evident for the former. This finding is in line with Gallagher's review (1999) reporting higher
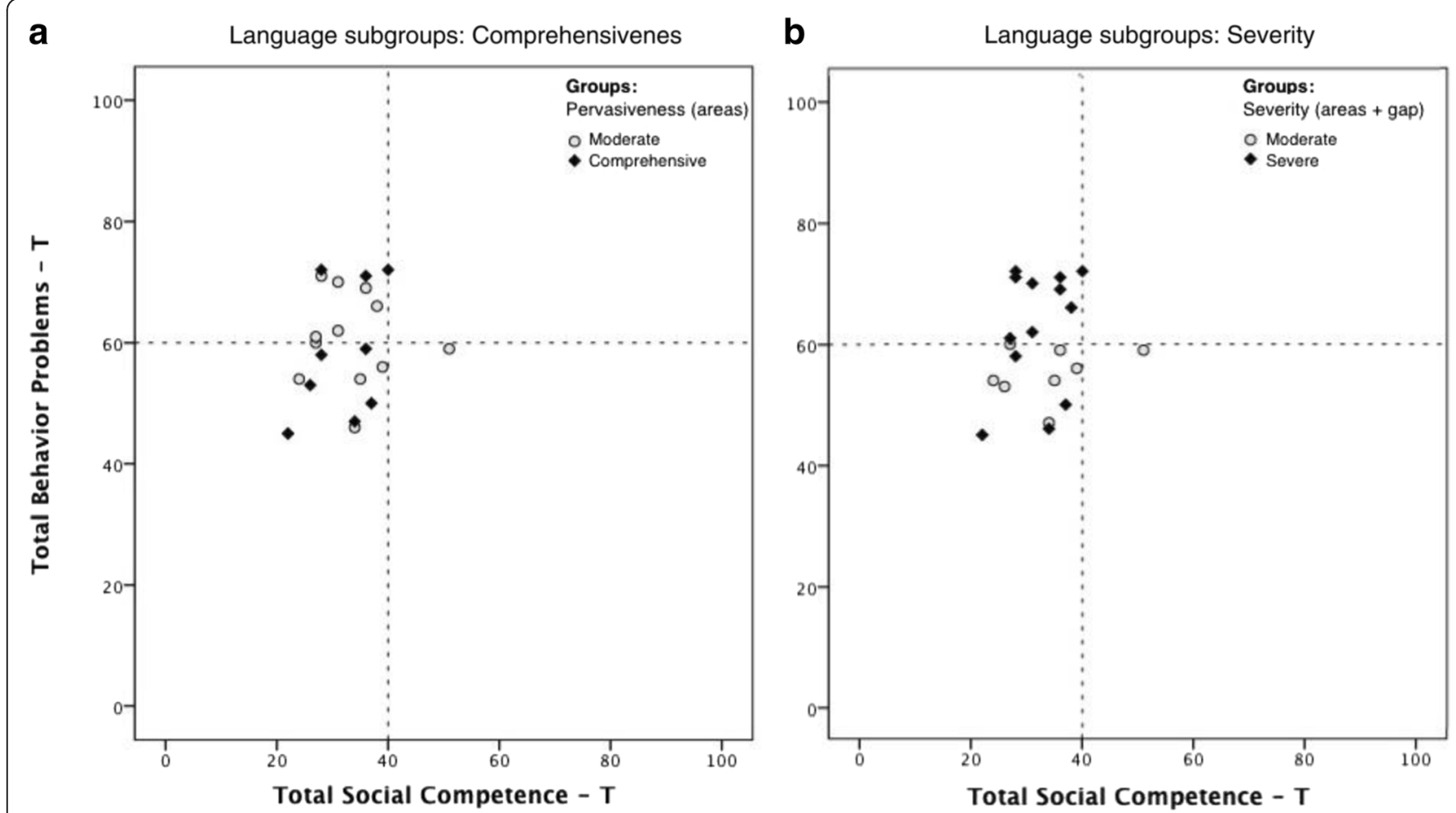

Fig. 2 Behavior problems and social competence according to language subgroups. Panel a illustrates language subgroups using the comprehensive criterion. Panel $\mathbf{b}$ illustrates language subgroups using the severity criterion 
Table 3 Behavioral problems depending on area of impairment and size of gap

\begin{tabular}{lllcc}
\hline Test & Gap ${ }^{\text {a }}$ & \multicolumn{2}{l}{ Behavioral Problems } & Statistics \\
\cline { 3 - 4 } & & Normal & "At risk of" & $\left(x^{2}\right)^{b}$ \\
\hline Expressive Vocabulary & Moderate & $8(67 \%)$ & $3(25 \%)$ & $4.196^{*}$ \\
& Severe & $4(33 \%)$ & $9(75 \%)$ & \\
Nonword Repetition & Moderate & $3(25 \%)$ & $3(25 \%)$ & .000 \\
& Severe & $9(75 \%)$ & $9(75 \%)$ & \\
CTOPP & Moderate & $3(25 \%)$ & $1(8 \%)$ & 1.200 \\
& Severe & $9(75 \%)$ & $11(92 \%)$ & \\
MLU & Moderate & $7(58 \%)$ & $2(18 \%)$ & $3.884^{*}$ \\
& Severe & $5(42 \%)$ & $9(82 \%)$ & \\
Pragmatics & Moderate & $2(22 \%)$ & $1(8 \%)$ & .810 \\
& Severe & $7(78 \%)$ & $11(92 \%)$ & \\
\hline
\end{tabular}

* Statistical significance at $p<.05$

a The gap was defined by the following criteria: for the Expressive Vocabulary, Nonword Repetition, MLU and Pragmatic tests, severe was equivalent to $\leq$ 2 year-gap and moderate to $>2$ year-gap. For the CTOPP, severe was equivalent to $<$ School Grade 1 and moderate to $\geq$ School Grade 1

${ }^{b}$ One Sample Chi-square Tests $(\mathrm{df}=1)$

internalizing behavior problems in school-aged children with SLI and in subjects with expressive language deficits.

The only subscales in which the percentage of behavior problems was similar to population rates were "Rule breaker" and "Somatic". Although the rule breaking profile is common among young children with SLI, aggressive problems may be replaced by a more withdrawn style in some children (Conti-Ramsden and Botting 2004), especially as they grow older. For the somatic subscale, although there is evidence showing that 4- to 6- year-olds with expressive language disorders were more likely to show "somatic complaints" (Willinger et al. 2003), no other studies, to our knowledge, have reported somatic problems in children with language disorders.

With respect to the social competence scale of the CBCL, the vast majority of children with SLI (95.2\%) demonstrated problems with social competence, particularly in achieving satisfactory academic skills ("School": $57.1 \%$ ) and engaging in activities such as sports, hobbies and/or group organizations ("Activities": $62.5 \%$ ). This is absolutely in line with previous work in the field showing that sociable behavior highly depends on language competence and is usually strongly impaired in children with SLI (Botting and Conti-Ramsden 2000; ContiRamsden and Botting 2004; St Clair et al. 2011).

To answer the second question of this study, we explored whether behavior problems and low social competence were associated with the severity of language deficits, according to two types of classification: the comprehensive and the severity criteria. Results showed that the severity - but not the comprehensive - criterion was associated with the risk of behavioral problems in this sample. No associations were found between the severity of language problems and social competence.
The fact that only the severity classification yielded significant associations is not surprising, given that this criterion tends to reflect more directly children's language competence. This finding suggests that in order to analyze the relation between the severity of language deficits and behavior, it is important to take into account the size of the gap in more than one area of language, which may be a better proxy of language functioning. This and other methodological issues concerning classification criterion may be crucial issues that might partially explain the controversial findings in the field (Monfort and Monfort 2012).

However, the absence of association between the severity of language deficits and low social competence was not predicted (Hart et al. 2004), and deserves some speculation. As mentioned above, almost all children in this sample showed low social competence, and this may be related to the fact that we selected only children with substantial expressive language problems. We are therefore working with children at the bottom range of language impairments. It is possible that small variations in language performance within this group were not enough to reflect changes in social competence. It should be explored whether different patterns would emerge if a heterogeneous group of children was studied, including children with mild language deficits. If patterns do change, there will be evidence to suggest that the relation between language impairment and low social competence is not linear, and requires a minimal proficiency in language to arise.

Behavior problems, on the other hand, showed significant association with language deficits in this sample. Children with severe language impairment showed higher behavior problems than children with moderate language impairment. Interestingly, the type of behaviors assessed through the CBCL does not necessarily depend on language to be performed. This scale taps anxious, withdrawn and aggressive behaviors, as well as problems related to attention and thought. It cannot be argued, therefore, that the relation between behavior and language skills in this sample of SLI stands only for initiatives that are largely carried out by using language, as suggested by (Hart et al. 2004). Alternatively, this result seems to corroborate previous findings showing that language competence relates to behavior in general (Lindsay et al. 2007; Van Agt et al. 2011; van Daal et al. 2007; St Clair et al. 2011), probably reflecting a cascade of indirect effects.

In this particular sample, post hoc analysis indicated that the lexical and grammatical domains accounted for the significant associations between the severity of language impairment and the classification of behavioral problems. These domains were assessed by tests of expressive vocabulary and mean length of utterance, two 
important measures of expressive language competence. These findings are in accordance with van Daal et al. (2007) who demonstrated that grammatical, semantic and pragmatic abilities predicted different types of behavior. We believe that the absence of association between the severity of pragmatic deficits and behavior problems in this sample might have been again a consequence of the characteristics of this homogeneous group. Because we assessed a group of children with moderate to severe language impairment, all children demonstrated pragmatic problems and most of them $(85.7 \%)$ showed more than a 2-year-gap in this area. If we had included children with mild language deficits in this sample, associations between pragmatics and behavior could have appeared.

It is also important to notice that because SLI is more likely to affect boys than girls (Whitehouse 2010), our sample was biased towards the male gender. We are aware that gender differences could have influenced the effects reported in this study, given that boys tend to show more externalizing problems than girls (Ketelaars et al., 2010; Conti-Ramsden et al. 2013). However, the opposite pattern (girls experiencing more problems than boys) is usually reported for internalizing problems (Conti-Ramsden et al. 2013), which was actually the most frequent type of behaviors problems reported in this sample. Besides that, all language groups comprised mainly boys (at least $70 \%$ ) and we still found a significant association between behavioral problems and the severity of language deficits. We understand therefore that our findings reflect true associations between behavior problems and language impairments, above and beyond potential gender differences.

This is the first Brazilian study to our knowledge to explore the relation between language deficits, behavior problems and social competence in a sample of children with SLI. It is important to acknowledge that the small number of subjects in this sample poses a limitation to the study. However, the adoption of different criteria for classifying the severity of language deficits and analyzing its relation with behavior problems and social competence represents an innovative approach and has led to interesting and new findings in the field.

\section{Conclusions}

The study provides cross-cultural evidence to support the existence of behavior problems and low social competence in children with SLI. Our findings point to the need of using a combination of measures to classify the severity of language problems rather than a single dimension. Adopting this classification, we found that language deficits were associated with behavior problems but not with reduced social competence, and this association was mainly driven by the performance in the lexical and grammatical domains.

\section{Competing interests}

The authors have no competing interests.

\section{Authors' contributions}

MLP, TN and DMB participated in the research design. MLP, AMC and TN participated in data collection. MLP and AMC wrote the paper; and TN and DMB revised the paper. All authors participated in data analysis. All authors read and approved the final manuscript.

\section{Author details}

'Universidade Federal de São Paulo, Sao Paulo, Brazil. ' Universidade de São Paulo, Sao Paulo, Brazil.

Received: 10 March 2016 Accepted: 7 April 2016

Published online: 22 April 2016

\section{References}

Achenbach TM, Rescorla LA. Menthal Health practioners'guide for the Achenbach System of Empirically Based Assessment (ASEBA). 4th ed. Burlington: University of Vermont, Research Center for children, Youth \& Families; 2004.

Araújo K d. Verificação da Extensão Média dos Enunciados como Instrumento de Desenvolvimento Gramatical em Crianças entre 2:0 e 4:7 anos. São Paulo: Universidade de São Paulo; 2003 (Master).

Befi-Lopes DM. Vocabulário. In: Andrade CRFd, editor. ABFW: Teste de Linguagem infantil nas áreas de fonologia, vocabulário, fluência e pragmática. Carapicuíba: Pró-Fono; 2004. p. 33-50.

Beitchman JH, Nair R, Clegg M, Ferguson B, Patel PG. Prevalence of psychiatric disorders in children with speech and language disorders. J Am Acad Child Psychiatry. 1986;25(4):528-35. doi:10.1016/S0002-7138(10)60013-1.

Bordin IAS, Mari JJ, Caeiro MF. Validação da versão brasileira do Child Behavior Checklist (CBCL) - Inventário de Comportamentos da Infância e da Adolescência: dados preliminares. Rev Bras Psiquiatr. 1995;17(2):55-66. doi:10.1590/S1516-44462000000600015.

Bordin IAS, Rocha MM, Paula CS, Teixeira MC, Achenbach TM, Rescorla LA, et al. Child Behavior Checklist (CBCL), Youth Self-Report (YSR) and Teacher's Report Form (TRF): an overview of the development of the original and Brazilian versions. Cad Saude Publica. 2013;29(1):13-28. doi:10.1590/S0102-311X2013000100004.

Botting N, Conti-Ramsden G. Social and behavioural difficulties in children with language impairment. Child Lang Teach Ther. 2000;16(2):105-20. doi:10.1177/026565900001600201.

Brinton B, Fujiki M. Social competence in children with language impairment: Making connections. Semin Speech Lang. 2005;26(3):151-9. doi:10.1055/s-2005-917120.

Conti-Ramsden G, Botting N. Social difficulties and victimization in children with SLI at 11 years of age. J Speech Lang Hear Res. 2004:47(1):145-61. doi:10.1044/1092-4388(2004/013).

Conti-Ramsden G, Mok PLH, Pickles A, Durkinc K. Adolescents with a history of specific language impairment (SLI): Strengths and difficulties in social, emotional and behavioral functioning. Res Dev Disabil. 2013;34(11):4161-9. doi:10.1016/j.ridd.2013.08.043.

Del Prette ZAP, Rocha MM, Silvares EFM, Del Prette A. Social skills and psychological disorders: Converging and criterion-related validity for YSR and IHSA-Del-Prette in adolescents at risk. Univ Psychol. 2012;11(3):941-55.

Fernandes FD. Pragmática. In: Andrade CRFd, editor. ABFW: Teste de Linguagem infantil nas áreas de fonologia, vocabulário, fluência e pragmática. Carapicuíba: Pró-Fono; 2004. p. 83-97.

Gallagher TM. Interrelationships among children's language, behavior, and emotional problems. Top Lang Disord. 1999;19(2):1-15. doi:10.1097/ 00011363-199902000-00003.

Gregl A, Kirigin M, Bilać S, Sućeska Ligutić R, Jaksić N, Jakovljević M. Speech comprehension and emotional/behavioral problems in children with specific language impairment (SLI). Coll Antropol. 2014;38(3):871-7.

Hart Kl, Fujiki M, Brinton B, Hart CH. The relationship between social behavior and severity of language impairment. J Speech Lang Hear Res. 2004;47(3):647-62. doi:10.1044/1092-4388(2004/050).

Helland WA, Helland T, Heimann M. Language profiles and mental health problems in children with specific language impairment and children with ADHD. J Atten Disord. 2014;18(3):226-35. doi:10.1177/1087054712441705. 
Hollo A, Wehby JH, Oliver RM. Unidentified language deficits in children with emotional and behavioral disorders: a meta-analysis. Except Child. 2014;80(2): 169-86. doi:10.1177/001440291408000203.

Ketelaars MP, Cuperus J, Jansonius K, Verhoeven L. Pragmatic language impairment and associated behavioural problems. Int I Lang Commun Disord. 2010;45(2):204-14. doi:10.3109/13682820902863090.

Lindsay G, Dockrell JE. Longitudinal patterns of behavioral, emotional, and social difficulties and self-concepts in adolescents with a history of specific language impairment. Lang Speech Hear Serv Sch. 2012;43:445-60. doi:10.1044/0161-1461(2012/11-0069).

Lindsay G, Dockrell JE, Letchford B, Mackie C. Self esteem of children with specific speech and language difficulties. Child Lang Teach Ther. 2002;18(2): 125-43. doi:10.1191/0265659002ct2310a.

Lindsay G, Dockrell JE, Strand S. Longitudinal patterns of behaviour problems in children with specific speech and language difficulties: child and contextual factors. Br J Educ Psychol. 2007;77(4):811-28. doi:10.1348/000709906X171127.

Macharey G, von Suchodoletz W. Perceived stigmatization of children with speech-language impairment and their parents. Folia Phoniatr Logop. 2008; 60(5):256-63. doi:10.1159/000151763.

Mok PL, Pickles A, Durkin K, Conti-Ramsden G. Longitudinal trajectories of peer relations in children with specific language impairment. J Child Psychol Psychiatry. 2014;55(5):516-27. doi:10.1111/jcpp.12190.

Monfort I, Monfort M. Utilidad clínica de las clasificaciones de los trastornos del desarrollo del lenguaje. Rev Neurol. 2012;54(Supl 1):S147-54.

Noterdaeme M, Amorosa H. Evaluation of emotional and behavioral problems in language impaired children using the child behavior checklist. Eur Child Adolesc Psychiatry. 1999;8(2):71-7.

Petersen IT, Bates JE, D'Onofrio BM, Coyne CA, Lansford JE, Dodge KA, et al. Language ability predicts the development of behavior problems in children. J Abnorm Psychol. 2013;122(2):542-57. doi:10.1037/a0031963.

Rodrigues A, Befi-Lopes DM. Short-term phonological memory in preschool children. CoDAS. 2013;25(5):422-8. doi:10.1590/S2317-17822013000500005.

Schoon I, Parsons S, Rush R, Law J. Children's language ability and psychosocial development: a 29-year follow-up study. Pediatrics. 2010;126(1):e73-80. doi:10.1542/peds.2009-3282.

Semel EM, Wiig EH, Secord W. Clinical evaluation of language fundamentalsrevised. San Antonio: The Psychological Corporation; 1987.

St Clair MC, Pickles A, Durkin K, Conti-Ramsden G. A longitudinal study of behavioral, emotional and social difficulties in individuals with a history of specific language impairment (SLI). J Commun Disord. 2011;44(2):186-99. doi:10.1016/j.jcomdis.2010.09.004.

Stark RE, Tallal P. Selection of children with specific language deficits. J Speech Hear Disord. 1981;46(2):114-22. doi:10.1044/jshd.4602.114.

Van Agt $H$, Verhoeven L, Van Den Brink G, De Koning H. The impact on socioemotional development and quality of life of language impairment in 8-yearold children. Dev Med Child Neurol. 2011;53(1):81-8. doi:10.1111/j.1469-8749. 2010.03794.X.

van Daal J, Verhoeven L, van Balkom H. Behaviour problems in children with language impairment. J Child Psychol Psychiatry. 2007;48(11):1139-47. doi:10.1111/j.1469-7610.2007.01790.x

Wagner R, Torgesen J, Rashotte C. Comprehensive test of phonological processing. Austin: PRO-ED; 1999.

Whitehouse AJO. Is there a sex ratio difference in the familial aggregation of specific language impairment? A meta-analysis. J Speech Lang Hear Res. 2010;53(4):1015-25. doi:10.1044/1092-4388(2009/09-0078).

Willinger U, Brunner E, Diendorfer-Radner G, Sams J, Sirsch U, Eisenwort B. Behaviour in children with language development disorders. Can J Psychiatry. 2003;48(9):607-14.

Yew SG, O'Kearney R. Emotional and behavioural outcomes later in childhood and adolescence for children with specific language impairments: metaanalyses of controlled prospective studies. J Child Psychol Psychiatry. 2013; 54(5):516-24. doi:10.1111/jcpp.12009.

\section{Submit your manuscript to a SpringerOpen ${ }^{\circ}$ journal and benefit from:}

- Convenient online submission

- Rigorous peer review

- Immediate publication on acceptance

- Open access: articles freely available online

- High visibility within the field

- Retaining the copyright to your article

Submit your next manuscript at $\gg$ springeropen.com 